\title{
Cytomegalovirus pneumonia occuring soon after initiation of highly active antiretroviral therapy in an infant
}

\author{
OP Kitchin, R Masekela, A Pentz, J Potgieter, MK Mensah, C Els, D White, RJ Green
}

Omolemo Kitchin, Refiloe Masekela, Adele Pentz, Jeane Potgieter, Marian Kwofie-Mensah, Carla Els, Debbie White, Robin Green Steve Biko Academic Hospital and University of Pretoria. E-mail: omolemo.kitchin@up.ac.za

\begin{abstract}
A two-month-old HIV-infected infant was ventilated for very severe Pneumocystis jiroveci pneumonia. After successful extubation, he was started on antiretroviral therapy. He developed a proven cytomegalovirus infection, localising as pneumonia. This required repeated ventilation. He was extubated after six weeks and completed 32 days of ganciclovir.
\end{abstract}

(P) Peer reviewed. (Submitted: 2011-01-31, Accepted: 2011-03-18). @ SAJEI

South Afr J Epidemiol Infect 2011;26(2):90-91

\section{Introduction}

Reports on immune reconstitution inflammatory syndrome (IRIS) in children following highly active antiretroviral therapy (HAART) are limited. Tuberculosis (TB) Bacillus CalmetteGuerin (BCG) IRIS is the most commonly reported disease. The prevalence of cytomegalovirus (CMV) in patients with IRIS is unknown. We are reporting on the first case of proven CMV pneumonia IRIS occurring within four days of starting HAART. We hope this will increase awareness and also illustrate the need for guidelines on CMV IRIS in children.

\section{Case report}

Our patient, a two-month-old boy, was admitted to the paediatric intensive care unit with very severe pneumonia requiring respiratory support. His mother did not enrol in the prevention of mother-to-child transmission (PMTCT) programme. He was ventilated using a lung protection strategy with positive end-expiratory pressure (PEEP) of $8 \mathrm{cmH}_{2} \mathrm{O}$, tidal volume of $6 \mathrm{ml} / \mathrm{kg}$ predicted for weight, and with a fraction of inspired oxygen of 0.6. Endotracheal aspirates were collected for Pneumocystis jiroveci immunofluorescence, viral identification, bacterial and TB culture. Blood cultures, HIV DNA polymerase chain recation (PCR) (Ampliprep instrument real-time qualitative PCR) and blood CMV viral load (Cobas Amplicor, Roche Diagnostics) were also performed.

The infant was treated with ampicillin and amikacin for five days, trimethoprim-sulfamethoxazole for 21 days, prednisone for 14 days and ganciclovir for five days. As per our protocol, ganciclovir was stopped when the blood CMV viral load reached undetectable levels. His HIV DNA PCR was positive and he was worked up for HAART. HIV viral load (Nuclisens instrument, BioMerieux Diagnostics) was included in the work-up. The rest of the patient's pre-HAART results are illustrated in Table I. The infant was extubated after 11 days, and successfully weaned to nasal prong oxygen at a flow of $2 \mathrm{l} /$ minute. Endotracheal aspirates and blood cultures performed two days before extubation were negative for bacterial growth. HAART was started on day 10. Four days after starting HAART, the child deteriorated clinically and radiologically and required reventilation. Repeat investigations demonstrated an increased blood CMV viral load. His CD4 count had also risen and his HIV viral load had fallen. This occurred in the absence of other infections (see Table I: post-HAART). Ganciclovir was restarted, and 32 days later a repeat test of blood CMV viral load was undetectable. At no point was HAART stopped. The child was extubated after six weeks and weaned to nasal prong oxygen.

Table 1: Investigations performed before and after HAART was initiated

\begin{tabular}{|l|l|l|}
\hline & \multicolumn{1}{|c|}{ Pre- HAART } & \multicolumn{1}{c|}{ Post-HAART } \\
\hline PJP IFA & \multicolumn{1}{|c|}{ Positive } & \multicolumn{1}{c|}{ Negative } \\
\hline CMV VL $(\log )$ & Undetectable & $1,000,000$ copies $/ \mathrm{ml}(\log 6)$ \\
\hline CD4 count $(\%)$ & $304 \times 106 / l(42.33 \%)$ & $1,833 \times 106 / l(44.8 \%)$ \\
\hline HIV VL (log) & $4,800,000$ copies/ml (log 6.68) & 19,000 copies/ml (log 4.27) \\
\hline ETA (bacteria) & Negative & Negative \\
\hline ETA (viruses) & Negative & Negative \\
\hline ETA (TB) & Negative & Negative \\
\hline
\end{tabular}

PJP IFA= Pneumocystis jiroveci immunoflourescence antibody, CMV VL= cytomegalovirus viral load, HIV VL= human immunodeficiency virus viral load, $\mathrm{ETA}=$ endotracheal aspirate, $\mathrm{TB}=$ tuberculosis, $\mathrm{HAART}=$ highly active antiretroviral therapy

\section{Discussion}

IRIS in children, especially infants, is infrequently reported in the literature. This may change, however, as more clinicians implement the World Health Organization recommendation of $2008,{ }^{1}$ of starting infants who are HIV-infected on HAART, irrespective of their immunological or clinical status. This policy change was motivated by the study of Violari et al. ${ }^{2}$ The 
challenge is the recognition and investigation of these infants and this may be an even a bigger challenge for the developing world with limited resources. The commonly reported organisms reported to cause IRIS are Mycobacterium tuberculosis, TB BCG, nontuberculous Mycobacterium, skin manifestations of herpes zoster, impetigo and tinea capitis. ${ }^{3-5}$ Only one case of CMV pneumonia IRIS has been reported. ${ }^{5}$ In this case, the onset of symptoms occurred nine days after starting HAART. Our case suggests CMV pneumonia occurred four days after starting HAART. These two cases imply that the presentation of symptoms for CMV IRIS is earlier than other forms of IRIS. ${ }^{6}$ We used a real-time quantitative PCR to detect the presence of CMV on admission, and at the onset of deterioration of symptoms. Although there are no established cut-points for blood CMV viral load, 1,000,000 copies/ml must be considered significant if symptoms recur after initial resolution. In addition, the viral load became undetectable 32 days after starting ganciclovir. At no point was HAART interrupted in our patient. The infant did not develop one of the established side- effects of ganciclovir, despite its addition to HAART.

Our patient met the case definition for IRIS, that is, he demonstrated evidence of clinical response to HAART with a significant increase in CD4 count and more than $1 \log _{10}$ decrease in his HIV viral load. ${ }^{4}$ Even though the pathogenesis of IRIS is still poorly understood, it is postulated that during the recovery of the immune system, there is a rapid recovery of pathogen-specific Th1 cells directed at extracellular pathogens, while the recovery of $T$ regulatory cells lags

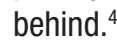

We present this case to alert physicians to be more vigilant in looking for unusual pathogens (especially CMV) in infants started on HAART and displaying symptoms suggestive of IRIS. In addition, we highlight the potential for CMV IRIS to occur earlier. We would encourage guidelines on HIV management in children, especially in resource-poor settings where the prevalence could be higher than presently reported, to explore CMV IRIS.

\section{References}

World Health Organization. Report of the WHO Technical Reference Group, Paediatric HIV/ART Care Guideline Group Meeting. Geneva, Switzerland 2008. http://www.who.int/hiv/pub/paediatric/WHO_Paediatric_ART guideline_rev_mreport_2008.pdf. (Accessed October 2010)

2. Violari A, Cotton MF, Gibb DM, et al. Early antiretroviral therapy and mortality among HIV-infected infants. N Eng J Med 2008; 359: 2233-2244

3. Rabie H, Meyers T, Cotton MF. Immune Reconstitution Inflammatory Syndrome in children. S Afr J HIV Med 2009; 10 70-75

4. Boulware DR, Callens S, Pahwa S. Pediatric HIV immune reconstitution inflammatory syndrome. Curr Opin HIV AIDS 2008; 3: 461-467

5. Smith K, Kuhn L, Coovadia A, et al. Immune reconstitution inflammatory syndrome among HIV-infected South African infants initiating antiretroviral therapy. AIDS 2009; 23: 1097-1107

6. Puthanakit $\mathrm{T}$, Oberdorfer P, Akarathum $\mathrm{N}$, et al. Immune reconstitution after highly active antiretroviral therapy in Human Immunodeficiency Virus-infected Thai children. Pediatr Infect Dis J 2006; 25: 53-58 